\title{
A Categorization Tool for Fabric Systems used in Firefighters' Clothing based on their Thermal Protective and Thermo-phys- iological Comfort Performances
}

\begin{abstract}
Fabric systems used in firefighters' thermal protective clothing should possess optimal thermal protective and thermo-physiological comfort performances. However, fabric systems which have very high thermal protective performance results have very low thermo-physiological comfort performance. As these performances are inversely related, a categorization tool based on these two performances can help in finding the best balance between them. Thus, this study is aimed at developing a tool for categorizing fabric systems used in protective clothing. For this, a set of commercially available fabric systems were evaluated and categorized. The thermal protective and thermo-physiological comfort performances were measured by standard test methods and indexed into a normalized scale between 0 (low performances) to 1 (high performances). The indices data set was first divided into three clusters by using the k-means algorithm. Here, each cluster had a centroid representing a typical Thermal Protective Performance Index (TPPI) value and a typical Thermo-physiological Comfort Performance Index (TCPI) value. By using the ISO 11612:2015 and EN 469:2014 guidelines related to the TPPI requirements, the clustered fabric systems were divided into two groups: Group 1 (high thermal protective performance based fabric systems) and Group 2 (low thermal protective performance based fabric systems). The fabric systems in each of these TPPI based groups were further categorized based on the typical TCPI values obtained from the k-means clustering algorithm. In this study, these categorized fabric systems showed either high, or low thermal protective performance with low, or medium, or high thermo-physiological comfort performance. Finally, a tool for these categorized fabric systems was prepared and graphically presented. The allocations of the fabric systems within the categorization tool have been verified based on their properties (e.g., thermal resistance, weight, evaporative resistance) and construction parameters (e.g., woven, nonwoven, layers) which significantly affect the performances. In this way, we identified key characteristics among the categorized fabric systems which can be used to upgrade or develop high performance fabric systems. Overall, the categorization tool developed in this study could help clothing manufacturers or textile engineers select and/or develop appropriate fabric systems with maximum thermal protective performance and thermo-physiological comfort performance. Thermal protective clothing manufactured by using this type of newly developed fabric systems could provide better occupational health and safety to firefighters.
\end{abstract}

Keywords: fabric systems, firefighters' clothing, thermal protective performance, thermophysiological comfort performance, k-means clustering algorithm, fabric categorization tool

\section{Introduction}

Every year numerous firefighter burn injuries and deaths occur across the world [1-3]. In order to reduce burn injuries and fatalities, fabric systems used in firefighters' thermal protective clothing should provide adequate burn injury protection under fire conditions [4-8]. However, the thermo-physiological comfort of firefighters is another aspect which could become 
critical with regard to heat stress and concomitant health related issues. For this reason, fabric systems should also effectively transmit the metabolic-heat and sweat-vapor from firefighters' bodies to the ambient environment [9-12]. The effective transmission of metabolic-heat and sweat-vapor could mitigate the heat stress related deaths of firefighters by maintaining their core body temperature below $38.5^{\circ} \mathrm{C}$. A fabric system used in firefighters' thermal protective clothing should possess optimal thermal protective and thermo-physiological comfort performances.

Extensive research has investigated the thermal protective and thermo-physiological comfort performances of fabric systems used in firefighters' clothing under fire conditions (radiant heat, flame) and ambient environments (warm to cold temperature, high to low relative humidity), respectively $[9,10,13-17]$. Contextually, it is notable that the available product standards (e.g., EN 469, ISO 11612) for the certification of protective clothing mainly put emphasis on the thermal protective performance with limited information regarding the thermophysiological comfort performance. In fact, the recommendations obtained from the product standards support the maximization of protective performance while neglecting thermo-physiological comfort performance. By controlling the fabric properties, thermal protective performance of a fabric system can be increased. However, a fabric system with very high thermal protective performance results in very low thermo-physiological comfort performance. As these performances are inversely related, a categorization tool based on the thermal protective and thermo-physiological comfort performances can help in finding the best balance between these two performances, and thus guide clothing manufacturers and/or fire stations' clothing procurement managers to select an appropriate fabric system for the clothing based on their requirements for end-uses. Nevertheless, no studies have been carried out in this direction yet.

The present study is aimed at developing a tool for categorizing a fabric system used for clothing systems based on thermal protective and thermo-physiological comfort performances. For this, a set of commercially available fabric systems were categorized based on their thermal 
protective and thermo-physiological comfort performances; and, the categorized fabric systems were graphically presented through a tool. The allocations of fabric systems within the categorization tool are verified based on physical property and construction parameters which significantly affect performance. Finally, this paper identified key characteristics among the categorized fabric systems that can be used in upgrading or developing high performance fabric systems.

\section{Methodology}

\subsection{Evaluation of fabric properties}

Layered fabric systems are commonly used in firefighters' protective clothing both in Europe and North America. Therefore, a set of commercially available single- and multi-layered fabric systems of different fiber content and constructions (weave patterns, number/types/arrangements of layers) were selected; and, the properties of these fabric systems were measured by following the respective standards (Table 1).

Table 1: Selected fabric systems and their properties

\begin{tabular}{|c|c|c|c|c|c|c|c|c|}
\hline \multirow{2}{*}{\multicolumn{2}{|c|}{ Fabric Systems }} & \multirow{3}{*}{$\begin{array}{l}\begin{array}{c}\text { Fiber Content and } \\
\text { Constructions }\end{array} \\
50 \% \text { Meta-aramid/50\% } \\
\text { Fire Retardant (FR) vis- } \\
\text { cose rayon woven fabric }\end{array}$} & \multicolumn{6}{|c|}{ Properties } \\
\hline & & & \multirow{2}{*}{$\begin{array}{r}\begin{array}{c}\mathbf{W}^{\mathbf{a}} \\
\left(\mathrm{g} / \mathrm{m}^{2}\right)\end{array} \\
197.0\end{array}$} & \multirow{2}{*}{$\begin{array}{r}\begin{array}{c}\mathbf{T}^{\mathbf{b}} \\
(\mathrm{mm})\end{array} \\
0.4\end{array}$} & \multirow{2}{*}{$\begin{array}{c}\begin{array}{c}\mathbf{R}_{\mathbf{c t}} \mathbf{c} \\
\left({ }^{\circ} \mathrm{K} \cdot \mathrm{m}^{2} / \mathrm{W} \cdot 10^{-3}\right)\end{array} \\
12.9\end{array}$} & \multirow{2}{*}{$\begin{array}{c}\frac{{ }_{\left(\mathrm{cm}^{3} / \mathrm{cm}^{2} / \mathrm{s}\right)}^{\mathbf{A}}}{148.6} \\
148 .\end{array}$} & \multirow{2}{*}{$\begin{array}{c}\begin{array}{c}\mathbf{R}_{\mathbf{e t}} \mathbf{e}^{\mathbf{e}} \\
\left(\mathrm{m}^{2} \cdot \mathrm{Pa} / \mathrm{W}\right)\end{array} \\
3.0\end{array}$} & \multirow{2}{*}{$\begin{array}{c}\begin{array}{c}\mathbf{W S S}^{\mathbf{f}} \\
(\mathrm{mm} / \mathrm{s})\end{array} \\
2.8\end{array}$} \\
\hline \multirow{6}{*}{ Single-layered } & $\mathrm{S} 1$ & & & & & & & \\
\hline & S2 & $\begin{array}{l}\text { Meta-aramid woven fab- } \\
\text { ric }\end{array}$ & 243.7 & 0.6 & 8.9 & 90.0 & 2.5 & 4.3 \\
\hline & S3 & $\begin{array}{l}\text { Meta-aramid woven fab- } \\
\text { ric }\end{array}$ & 154.7 & 0.3 & 9.7 & 502.2 & 2.4 & 6.7 \\
\hline & S4 & $\begin{array}{l}\text { Meta-aramid woven fab- } \\
\text { ric }\end{array}$ & 229.8 & 0.4 & 9.4 & 91.4 & 3.3 & 6.8 \\
\hline & S5 & $\begin{array}{l}55 \% \quad \text { FR } \\
\text { modacrylic/45\% FR cot- } \\
\text { ton woven fabric }\end{array}$ & 367.3 & 0.7 & 13.0 & 44.3 & 3.6 & 0.5 \\
\hline & S6 & FR cotton woven fabric & 366.8 & 0.8 & 12.9 & 43.0 & 4.7 & 0.8 \\
\hline \multirow{2}{*}{$\begin{array}{l}\text { Multi-layered } \\
\text { [Outer Layer } \\
\text { (OL) shell fab- } \\
\text { ric + Middle } \\
\text { Layer (ML) }\end{array}$} & $\begin{array}{c}\text { M7 } \\
+ \\
+ \\
+\end{array}$ & $\begin{array}{l}\text { Meta-aramid woven fab- } \\
\text { ric }(\mathrm{OL})+\text { PTFE coated } \\
\text { meta-aramid PTFE dot- } \\
\text { ted nonwoven fabric } \\
(\mathrm{ML})+50 \% \text { meta-ara- } \\
\text { mid/50\% FR viscose } \\
\text { rayon woven fabric (IL) }\end{array}$ & 609.9 & 3.9 & 79.7 & 0 & 20.2 & 0.8 \\
\hline & M8 & $\begin{array}{l}\text { Meta-aramid woven fab- } \\
\text { ric }(\mathrm{OL}) \text { + PTFE coated }\end{array}$ & 547.5 & 3.9 & 80.0 & 0 & 15.8 & 0.5 \\
\hline
\end{tabular}




\begin{tabular}{|c|c|c|c|c|c|c|c|c|}
\hline \multirow{8}{*}{$\begin{array}{l}\text { moisture bar- } \\
\text { rier) + Inner } \\
\text { layer (IL) } \\
\text { thermal liner } \\
\text { (s) and/or fab- } \\
\text { ric(s)] }\end{array}$} & + & $\begin{array}{l}\text { meta-aramid nonwoven } \\
\text { fabric (ML acts as IL) }\end{array}$ & & & & & & \\
\hline & M9 & $\begin{array}{l}\text { Meta-aramid woven fab- } \\
\text { ric (OL) + PTFE coated } \\
\text { aramid nonwoven fabric } \\
(\mathrm{ML})+\text { Aramid regener- } \\
\text { ated nonwoven felt } \\
\text { quilted with } 50 \% \text { meta- } \\
\text { aramid } / 50 \% \text { FR viscose } \\
\text { rayon woven fabric (IL) }\end{array}$ & 673.8 & 4.9 & 127.7 & 0 & 25.4 & 0.3 \\
\hline & + & $\begin{array}{l}99 \% \text { aramid } / \% \text { beltron } \\
\text { woven fabric (OL) + } \\
\text { PTFE coated meta-ara- } \\
\text { mid nonwoven fabric } \\
(\mathrm{ML})+\text { Aramid fleece } \\
\left(\mathrm{IL}_{\text {layer1 } 1}\right)+50 \% \text { meta-ar- } \\
\text { amid } / 50 \% \text { viscose rayon } \\
\text { woven fabric }\left(\mathrm{IL}_{\text {layer } 2}\right)\end{array}$ & 635.2 & 3.2 & 82.7 & 0 & 15.6 & 3.3 \\
\hline & $\begin{array}{l}+ \\
+ \\
+\end{array}$ & $\begin{array}{l}\text { Meta-aramid woven fab- } \\
\text { ric (OL) + Polyurethane } \\
(\mathrm{PU}) \text { coated meta-ara- } \\
\text { mid nonwoven fabric } \\
(\mathrm{ML})+\text { Aramid woven } \\
\text { fabric (IL) }\end{array}$ & 592.1 & 3.9 & 95.4 & 0 & 23.9 & 1.9 \\
\hline & $\begin{array}{r}\text { M1 } \\
+ \\
+\end{array}$ & $\begin{array}{l}64 \% \quad \text { FR } \\
\text { rayon } / 35 \% \text { viscose } \\
\text { mid/1\% Antistatic wo- } \\
\text { ven fabric }(\mathrm{OL})+\text { PU } \\
\text { coated } 50 \% \text { meta-ara- } \\
\text { mid/50\% FR viscose } \\
\text { rayon nonwoven fabric } \\
(\mathrm{ML})+65 \% \text { FR viscose } \\
\text { rayon/35\% meta-aramid } \\
\text { woven fabric (IL) }\end{array}$ & 587.8 & 2.1 & 46.6 & 0 & 9.4 & 0.6 \\
\hline & $\begin{array}{l}+ \\
+ \\
+\end{array}$ & $\begin{array}{l}64 \% \text { FR } \\
\text { rayon/35\% miscose } \\
\text { mid/1\% Antistatic wo- } \\
\text { ven fabric }(\mathrm{OL})+\text { PTFE } \\
\text { coated } 50 \% \text { meta-ara- } \\
\text { mid/50\% FR viscose } \\
\text { rayon nonwoven fabric } \\
(\mathrm{ML})+65 \% \text { FR viscose } \\
\text { rayon/35\% meta-aramid } \\
\text { woven fabric (IL) }\end{array}$ & 599.8 & 2.3 & 49.3 & 0 & 10.0 & 0.5 \\
\hline & M14 & $\begin{array}{l}\text { Meta-aramid woven fab- } \\
\text { ric }(\mathrm{OL})+\mathrm{PTFE} \text { coated } \\
25 \% \text { meta-aramid/25\% } \\
\text { para-aramid/50\% basofil } \\
\text { nonwoven fabric (ML) + } \\
\text { Meta-aramid nonwoven } \\
\text { quilted with } 50 \% \text { meta- } \\
\text { aramid/50 FR viscose } \\
\text { rayon woven fabric (IL) }\end{array}$ & 493.0 & 2.3 & 71.0 & 0 & 16.8 & 4.3 \\
\hline & M15 & $75 \%$ meta-aramid $/ 23 \%$ & 520.5 & 2.1 & 61.8 & 1.0 & 12.2 & 2.6 \\
\hline
\end{tabular}




\begin{tabular}{|c|c|c|c|c|c|c|c|}
\hline $\begin{array}{l}+ \\
+ \\
+\end{array}$ & $\begin{array}{l}\text { para-aramid/2\% anti- } \\
\text { static woven fabric (OL) } \\
+ \text { PTFE coated aramid } \\
\text { nonwoven fabric (ML) }+ \\
\text { Meta-aramid (ILlayer1)+ } \\
93 \% \text { meta-aramid/5\% } \\
\text { para-aramid/2\% anti- } \\
\text { static woven fabric (IL- } \\
\text { layer2) } \\
\end{array}$ & & & & & & \\
\hline 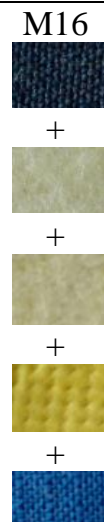 & $\begin{array}{l}75 \% \text { meta-aramid/23\% } \\
\text { para-aramid/2\% anti- } \\
\text { static woven fabric }(\mathrm{OL}) \\
+ \text { PTFE coated aramid } \\
\text { nonwoven fabric }(\mathrm{ML})+ \\
\text { Meta-aramid nonwoven } \\
\left.\text { fabric (IL } \mathrm{IL}_{\text {layer1 } 1}\right)+ \text { Meta- } \\
\text { aramid nano nonwoven } \\
\text { fabric (ILlayer2) }+93 \% \\
\text { meta-aramid/5\% para- } \\
\text { aramid/2\% antistatic } \\
\text { woven fabric (ILlayer3) }\end{array}$ & 514.8 & 2.2 & 65.6 & 0.8 & 13.0 & 3.4 \\
\hline $\begin{array}{l}\text { M17 } \\
\text { Prype } \\
+ \\
+ \\
+\end{array}$ & $\begin{array}{l}\text { Meta- and para-aramid } \\
\text { woven fabric (OL) + } \\
\text { PTFE coated aramid } \\
\text { nonwoven fabric (ML) + } \\
\text { PTFE coated aramid wo- } \\
\text { ven fabric (IL) }\end{array}$ & 568.1 & 3.0 & 83.3 & 0 & 12.8 & 3.2 \\
\hline+ & $\begin{array}{l}\text { Meta- and para-aramid } \\
\text { woven fabric (OL) + } \\
\text { PTFE coated aramid } \\
\text { nonwoven fabric (ML) + } \\
\text { Meta-aramid nonwoven } \\
\text { fabric (IL }\left(\mathrm{ILyyr}_{\text {lay } 1)+ \text { Meta- }}\right. \\
\text { aramid nano nonwoven } \\
\text { fabric (ILlayer2) }+93 \% \\
\text { meta-aramid/5\% para- } \\
\text { aramid/2\% antistatic } \\
\text { woven fabric (ILlayer3) }\end{array}$ & 496.7 & 2.1 & 64.2 & 0.8 & 14.2 & 3.0 \\
\hline 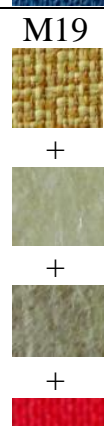 & $\begin{array}{l}\text { Meta- and para-aramid } \\
\text { woven fabric (OL) + } \\
\text { PTFE coated aramid } \\
\text { nonwoven fabric (ML)+ } \\
\text { Meta-aramid nonwoven } \\
\text { fabric (ILlayer1) }+93 \% \\
\text { meta-aramid/5\% para- } \\
\text { aramid } / 2 \% \text { antistatic } \\
\text { woven fabric (IL } \text { IL }_{\text {layer } 2)}\end{array}$ & 490.4 & 1.9 & 60.0 & 1.1 & 13.2 & 2.3 \\
\hline
\end{tabular}

N.B. Outer Layer (OL) shell fabric faces thermal exposures; Middle Layer (ML) moisture barrier is sandwiched between OL and Inner Layer (IL); and Inner Layer (IL) thermal liner(s) and/fabric(s) is arranged next to the ML and towards wearers' skin. ${ }^{\text {aW }}$ eight (W) measured by ISO 3801:1977 [18]; ' Thickness (T) measured by 
ISO 5084:1996 [19]; ' $T$ Thermal Resistance $\left(\mathrm{R}_{\mathrm{ct}}\right)$ measured by ISO 11092:2014 [20]; ${ }^{\mathrm{d} A i r}$ Permeability (AP) measured by ISO 9237:995 [21]; ${ }^{\mathrm{e}}$ Evaporative Resistance $\left(\mathrm{R}_{\mathrm{et}}\right)$ measured by ISO 11092:2014 [20]; ${ }^{\mathrm{f}}$ Water (or sweat) Spreading Speed (WSS) of the fabric layer in contact with wearers' skin and was measured by AATCC 195 [22].

\subsection{Evaluating and indexing the thermal protective performance of fabric systems}

The thermal protective performance of the selected fabric systems was measured under the conditions of $80 \mathrm{~kW} / \mathrm{m}^{2}$ flame exposure using Method A of ISO 9151:2016 test standard [23]. This flame test evaluates the thermal protective performance under the combined exposures of flame, radiant-heat, and hot gasses [24]. By using this test, the performance was measured by means of the Heat Transfer Index $\left(\mathrm{HTI}_{24}\right)$ (Table 2). Here, the $\mathrm{HTI}_{24}$ was measured using a copper sensor when the fabric systems were tested in contact with the sensor under the flame exposure [4]. $\mathrm{HTI}_{24}$ provides time to increase the surface temperature of the copper sensor by $24^{\circ} \mathrm{C}$. Notably, the $\mathrm{HTI}_{24}$ was used in evaluating the thermal protective performance of the fabric systems being evaluated because this value is used in EN 469:2014 to classify suitable fabrics for firefighters' thermal protective clothing. As per the standard, a fabric system with the high $\mathrm{HTI}_{24}$ value possesses the high thermal protective performance compared to a fabric system with the low $\mathrm{HTI}_{24}$ value.

Table 2: Thermal protective performance of fabric systems

\begin{tabular}{|c|c|c|}
\hline Fabric Systems & $\begin{array}{c}\text { Thermal Protective Performance } \\
\text { HTI }_{24} \text { (in sec.) as per ISO 9151:2016 standard] }\end{array}$ & $\begin{array}{c}\text { Thermal Protective Performance } \\
\text { Index (TPPI) }\end{array}$ \\
\hline S1 & 4.3 & 0.06 \\
\hline S2 & 4.5 & 0.07 \\
\hline S3 & 3.6 & 0.03 \\
\hline S4 & 4.0 & 0.05 \\
\hline S6 & 5.9 & 0.13 \\
\hline M7 & 5.7 & 0.12 \\
\hline M8 & 17.7 & 0.67 \\
\hline M9 & 14.9 & 0.54 \\
\hline M10 & 24.6 & 0.98 \\
\hline M11 & 16.0 & 0.59 \\
\hline M13 & 19.7 & 0.76 \\
\hline M14 & 14.5 & 0.52 \\
\hline M15 & 14.1 & 0.50 \\
\hline M16 & 14.6 & 0.53 \\
\hline M17 & 14.2 & 0.51 \\
\hline M18 & 15.2 & 0.55 \\
\hline M19 & 16.0 & 0.59 \\
\hline For the & 0.47 \\
\hline
\end{tabular}

For the categorization, $\mathrm{HTI}_{24}$ values of the selected fabric systems were indexed into a normalized scale of 0 (indication low thermal protective performance) to 1 (indicating high 
thermal protective performance) using Equation 1 and termed as a Thermal Protective Performance Index (TPPI) (Table 2). Here, the commonly and conveniently used min-max normalization approach was applied for establishing Equation 1 [25]. Notably, the minimum and maximum $\mathrm{HTI}_{24}$ values of our selected fabric systems (Table 2) were 3.6 and 24.6, respectively. And, these values were rounded up and down resulting in 3 and 25 as minimum and maximum, respectively, to be used in Equation 1.

$$
\mathrm{TPPI}_{\text {Fabric X }}=\frac{\left(\mathrm{HTI}_{24} \text { Value }\right)_{\text {Fabric X }}-\left(\text { Min. }_{\mathrm{HTI}}{ }_{24} \text { Value }\right)}{\left(\text { Max.HTI }_{24} \text { Value }- \text { Min.HTI }_{24} \text { Value }\right)}=\frac{\left(\mathrm{HTI}_{24} \text { Value }_{\mathrm{Fabric}-3}\right.}{(25-3)}, \quad \text { Equation } 1
$$

\subsection{Evaluating and indexing the thermo-physiological comfort performance of fabric systems}

The thermo-physiological comfort performance of the fabrics was measured using ISO 18640-1:2018 standard sweating guarded torso test method and a statistical equation provided by Annaheim et al. in 2016 (i.e., Equation 2) [9, 26]. As per this standard test method, at a defined ambient temperature $\left(20 \pm 0.5^{\circ} \mathrm{C}\right)$ and relative humidity $(50 \pm 5 \%)$, thermal resistance of the fabric $\left(\mathrm{R}_{\mathrm{ct}}\right.$ in $\left.\mathrm{m}^{2} . \mathrm{K} / \mathrm{W}\right)$ was measured during a dry phase i.e., a test with constant torso surface temperature of $35^{\circ} \mathrm{C}$ and without any sweating. As expected, the $\mathrm{R}_{\mathrm{ct}}$ values obtained from the dry phase torso test were similar (correlation coefficient and p-value was 0.99 and 0.001, respectively) to the $\mathrm{R}_{\mathrm{ct}}$ values presented in Table 1 i.e., measured by ISO 11092:2014 sweating guarded hot plate test. Immediately after the dry phase torso test, activity phase torso test was conducted i.e., consisting of a metabolic heat production of 500W (heating power to torso was $125 \mathrm{~W}$ ) and a sweat rate of $100 \mathrm{~g} / \mathrm{h}$ [corresponding to a human physical activity of 6 Mets $\left(290 \mathrm{~W} / \mathrm{m}^{2}\right)$ and sweat rate of $230 \mathrm{~g} / \mathrm{m}^{2} / \mathrm{h}$ ]. In the activity phase, the torso surface temperature initially started to cool down from $35^{\circ} \mathrm{C}$ and this initial cooling rate (IC in $\mathrm{K} / \mathrm{hr}$ ) was measured (Table 1). Based on $\mathrm{R}_{\mathrm{ct}}$ and IC, comparative Time to Heat Stress (cTHEST in minutes) was calculated using Equation 2. This cTHEST was interpreted as the thermo-physiological comfort performance for fabrics (Table 3). Here, a high value of cTHEST indicates a high thermo-physiological comfort performance for the fabric [9]. 
Table 3: Thermo-physiological comfort performance of fabric systems

\begin{tabular}{|c|c|c|c|}
\hline $\begin{array}{l}\text { Fabric } \\
\text { Systems }\end{array}$ & $\begin{array}{c}\text { Initial Cooling } \\
\text { Rate } \\
\text { IC in K/hr) }\end{array}$ & $\begin{array}{c}\text { Thermo-physiological Comfort } \\
\text { Performance [cTHEST (in minutes) as per } \\
\text { ISO 18640-1:2018 standard and Equation 2] }\end{array}$ & $\begin{array}{c}\text { Thermo-physiological } \\
\text { Comfort Performance } \\
\text { Index (TCPI) }\end{array}$ \\
\hline S1 & 8.0 & 124.4 & 0.78 \\
\hline S2 & 7.5 & 123.6 & 0.74 \\
\hline S3 & 13.5 & 128.0 & 0.92 \\
\hline S4 & 13.8 & 128.0 & 0.92 \\
\hline S5 & 1.4 & 119.2 & 0.57 \\
\hline S6 & 4.0 & 121.0 & 0.64 \\
\hline M7 & 6.5 & 118.5 & 0.54 \\
\hline M8 & 2.0 & 115.5 & 0.42 \\
\hline M9 & 3.5 & 114.0 & 0.36 \\
\hline M10 & 3.4 & 116.2 & 0.45 \\
\hline M11 & 2.3 & 114.8 & 0.39 \\
\hline M12 & 1.1 & 116.7 & 0.47 \\
\hline M13 & 0.0 & 115.6 & 0.42 \\
\hline M14 & 6.5 & 119.3 & 0.57 \\
\hline M15 & 10.6 & 122.2 & 0.69 \\
\hline M16 & 5.8 & 118.8 & 0.55 \\
\hline M17 & 4.9 & 116.7 & 0.47 \\
\hline M18 & 5.0 & 118.0 & 0.52 \\
\hline M19 & 10.0 & 121.7 & 0.67 \\
\hline
\end{tabular}

For the categorization, the cTHEST value of a fabric system was indexed into a normalized scale of 0 (low thermo-physiological comfort performance) to 1 (high thermo-physiological comfort performance) using Equation 3 and termed as a Thermo-physiological Comfort Performance Index (TCPI) (Table 3). Here, the commonly and conveniently used min-max normalization approach was applied for establishing Equation 3 [25]. The minimum and maximum cTHEST values of our selected fabric systems (Table 2) were 114 and 128 minutes, respectively. Nevertheless, based on our past experiences, the minimum cTHEST value of some rarely used fabric systems for firefighters' clothing could be down to 107.7 minutes. In order to maintain the nice-rounded-numbers, the minimum and maximum cTHEST values of the selected fabric systems were considered as 105 minutes and 130 minutes, respectively, in Equation 3. $(\mathrm{TCPI})_{\text {Fabric X }}=\frac{(\text { cTHEST Value })_{\text {Fabric } \mathrm{X}}-(\text { Min.cTHEST Value })}{(\text { Max.cTHEST Value }- \text { Min.cTHEST Value })}=\frac{(\text { cTHEST Value })_{\text {Fabric }}-105}{130-105}$,Equation 3 2.4 Procedure for the categorization of the fabric systems based on their thermal protective and thermo-physiological comfort performances 
At first, the TPPI (X-axis) and TCPI (Y-axis) values of all the fabric systems were plotted in an X-Y Scatter chart. Based on this chart, it was identified that these TPPI and TCPI values can be realistically divided into three clusters. Considering this, the data set (TPPI and TCPI values of all the fabric systems) was divided into three clusters by using k-means clustering algorithm. The execution of this algorithm in MATLAB ${ }^{\circledR}$ R2015b software resulted in representative centroids for each of the three clusters. Each of the centroids comprised a typical TPPI value and a typical TCPI value, where the Euclidian distance between the data set and the centroid of a cluster was lower in comparison to the distance between the same data set and the centroids of the other clusters. Furthermore, by using the EN 469:2014 and ISO 11612:2015 guidelines related to the TPPI values, the selected fabric systems were divided into different groups. The fabric systems in each group were further categorized based on the typical TCPI values. Finally, a tool comprising the categorized fabric systems was prepared and graphically presented through a figure in the results and discussion section of this paper. The allocation of the fabric systems within each category were also verified statistically based on the fabric systems' properties (e.g., weight, thickness, thermal resistance, air permeability, evaporative resistance, and/or water/sweat spreading speed) and construction parameters (e.g., number/types/arrangements of layers, and/or woven/nonwoven/permeable structure) that could significantly affect the performances. The key characteristics required to upgrade or develop fabric systems with improved thermo-physiological comfort performance while maintaining the required thermal protective performance is also theoretically discussed.

\section{Results and Discussion}

\subsection{Categorization of fabric systems based on their thermal protective and thermo-} physiological comfort performances

Using k-means clustering algorithm on the TPPI and TCPI values, fabric systems were divided into three clusters as shown in Figure 1. In this figure, as per the discussion in the methodology section, the centroid of each cluster represents a typical TPPI and a typical TCPI 
value. Clusters were identified as follows: Cluster 1 (fabric systems with medium range of thermal protective performance and medium range of thermo-physiological comfort performance): the typical TPPI value $=0.54($ range of TPPI values in Cluster $1: 0.44-0.67)$ and typical TCPI value $=0.52$ (range of TCPI values in Cluster 1: 0.42-0.69); Cluster 2 (fabric systems with high range of thermal protective performance and low range of thermo-physiological comfort performance): the typical TPPI value $=0.87$ (range of TPPI values in Cluster 2: 0.76-0.98) and typical TCPI value $=0.38$ (range of TCPI values in Cluster 2: 0.36-0.39); and Cluster 3 (fabric systems with low range of thermal protective performance and high range of thermo-physiological comfort performance): the typical TPPI value $=0.08$ (range of TPPI values in Cluster 3: $0.05-0.13$ ) and typical TCPI value $=0.76$ (range of TCPI values in Cluster 3: 0.57-0.92) Notably, according to ISO 11612:2015 standard, fabric systems with a TPPI value $\leq 0.05$ (HTI 24 value $\leq 4$ seconds) do not pass the standard for use in thermal protective clothing; so, these fabric systems are qualified as non-standard (NS) fabric systems (Figure 1). Also, as per EN 469:2014 guidelines, multi-layered fabric systems with a $\mathrm{HTI}_{24}$ value of $\geq 9$ seconds (or TPPI value of $\geq 0.27$ ) can be used in firefighters' protective clothing namely turnout gears. Nevertheless, according to the EN 469:2014 standard, requirements set for turnout gear fabric systems are $\mathrm{HTI}_{24}$ value of $\geq 13$ seconds (or TPPI value of $\geq 0.45$ ) and these systems can be classified as high performance Level 2 fabric systems. Interestingly, in Figure 1, Level 1 fabric systems in the EN 469 guideline $\left(9 \leq \mathrm{HTI}_{24}<13\right.$ or $\left.0.27 \leq \mathrm{TPPI}<0.45\right)$ could be grouped as providing a medium level of thermal protective performance; and, the rest of the fabric systems (except NS fabric systems) having $4 \leq \mathrm{HTI}_{24}<9$ or $0.05 \leq \mathrm{TPPI}<0.27$ could be grouped as proving a low level of thermal protective performance. However, a medium level of thermal protective performance based fabric system is unlikely to be used in firefighters' turnout gear; and, as shown in Figure 1, only 1 fabric system (out of the 19 commercially available fabric systems used in this study) belongs to this group. Considering this, the present study merged the medium levels thermal protective performance based fabric systems $\left(9 \leq \mathrm{HTI}_{24}<13\right.$ or $0.27 \leq \mathrm{TPPI}<$ 
0.45) with the low levels thermal protective performance based fabric systems $\left(4 \leq \mathrm{HTI}_{24}<9\right.$ or $0.05 \leq \mathrm{TPPI}<0.27$ ) and divided the total fabric systems into 2 groups (high and low thermal protective performance based fabric systems) instead of 3 groups (high, medium, and low thermal protective performance based fabric systems) based on TPPI (Figure 1). In summary, based on ISO 11612:2015 and EN 469:2014 guidelines related to the TPPI, the fabric systems with TPPI $\geq 0.45$ and $0.05 \leq$ TPPI $<0.45$ can be divided into Group 1 (similar to the high thermal protective performance based Level 2 fabric systems as per EN 469:2014 standard) and Group 2 (low thermal protective performance based fabric systems as per this study) fabric systems, respectively (Figure 1).

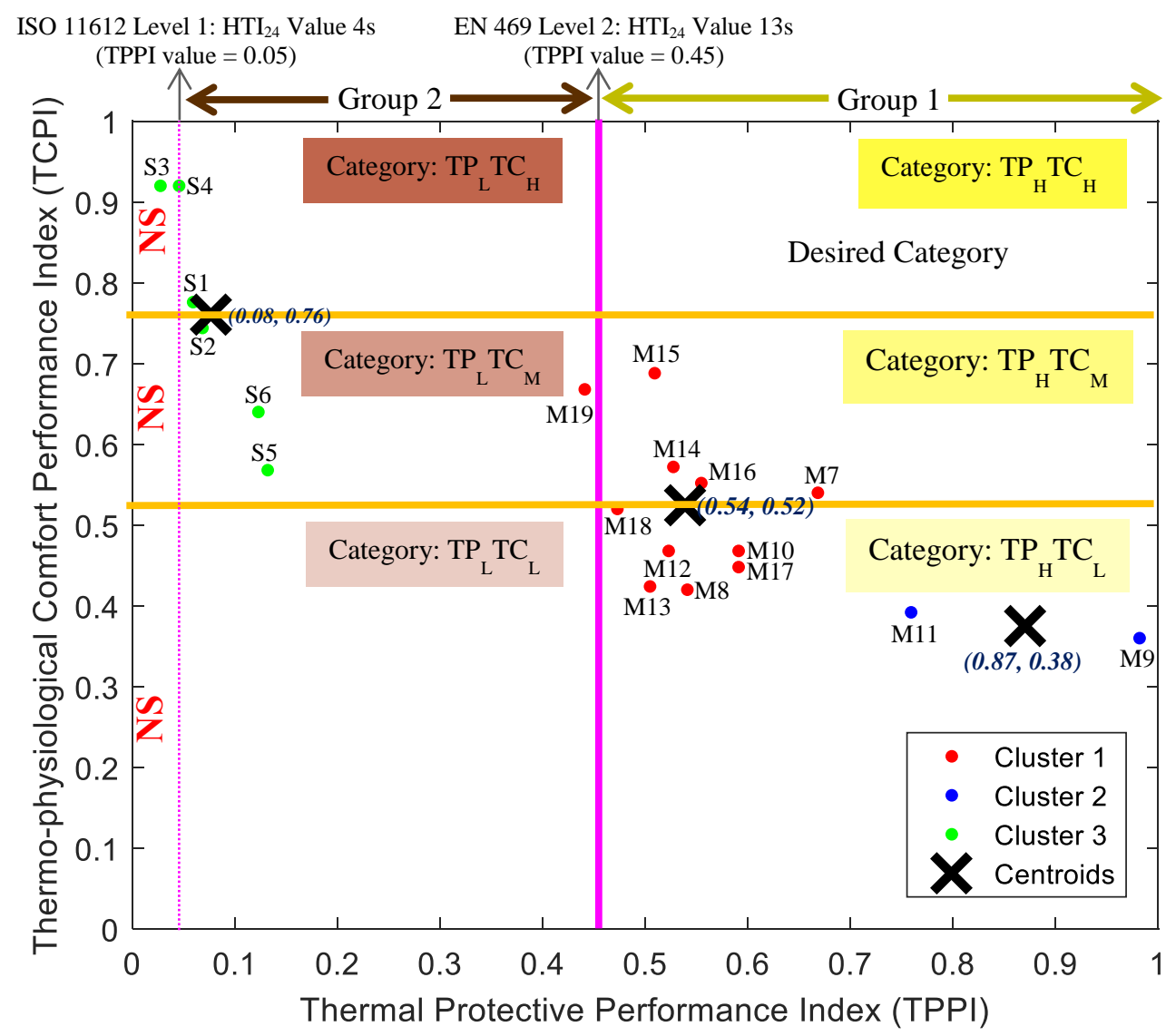

Figure 1: Categorization tool for fabrics based on their thermal protective and thermo-physiological comfort performances $(\mathrm{TP}=$ Thermal Protection; $\mathrm{TC}=$ Thermo-physiological Comfort; $\mathrm{L}=$ Low; $\mathrm{M}=$ Medium; $\mathrm{H}=$ High)

Furthermore, the thermo-physiological comfort performance of the fabric systems in Group 1 and Group 2 varies from low to high as their TCPI values increase from 0-1 (usually 
TCPI values lie between 0.36-0.69 for Group 1 and 0.57-0.92 for Group 2). Therefore, by using the typical TCPI values of the clusters, the fabric systems of these two groups can further be categorized. In the following sections, the categorization of these two groups of fabric systems is thoroughly discussed; and, the allocation of the fabric systems within each category is verified based on their properties and constructions which affect the thermal protective and thermophysiological comfort performances.

Based on our previous studies [4, 24, 27, 28], among all the fabric system properties listed in Table 1, it has been found that only thermal resistance $\left(\mathrm{R}_{\mathrm{ct}}\right)$ is the most significant (pvalue $<0.05)$ property to directly affect the thermal protective performance of fabric systems. Whereas, weight (W), evaporative resistance $\left(\mathrm{R}_{\mathrm{et}}\right)$, and/or water/sweat spreading speed (WSS) of the fabric systems equally and significantly $(p$-value $=0.0001)$ affect the thermo-physiological comfort performance; here, W and $\mathrm{R}_{\mathrm{et}}$ indirectly, whereas, WSS directly affect the comfort performance. It is notable that $\mathrm{R}_{\mathrm{ct}}$ of the selected fabric systems in this study varied widely and they are directly associated with the $\mathrm{W}$ and $\mathrm{R}_{\mathrm{et}}$ (Figure 2 ). So, increasing the $\mathrm{R}_{\mathrm{ct}}$ could increase the thermal protective performance of the systems; however it could also lower the thermophysiological comfort performance by increasing the $\mathrm{R}_{\mathrm{et}}$ or $\mathrm{W}$. In order to simplify such complicated association between significant fabric properties and the performances, the allocation of fabric systems in each category is verified mainly based on the statistical mean and standard deviation values of the significant properties of the systems belonging to that category. Also, it has been found that some primary construction parameters of the fabric system, such as numbers, structures, and arrangement of the layers in the system significantly affect the thermal protective and thermo-physiological comfort performances. 


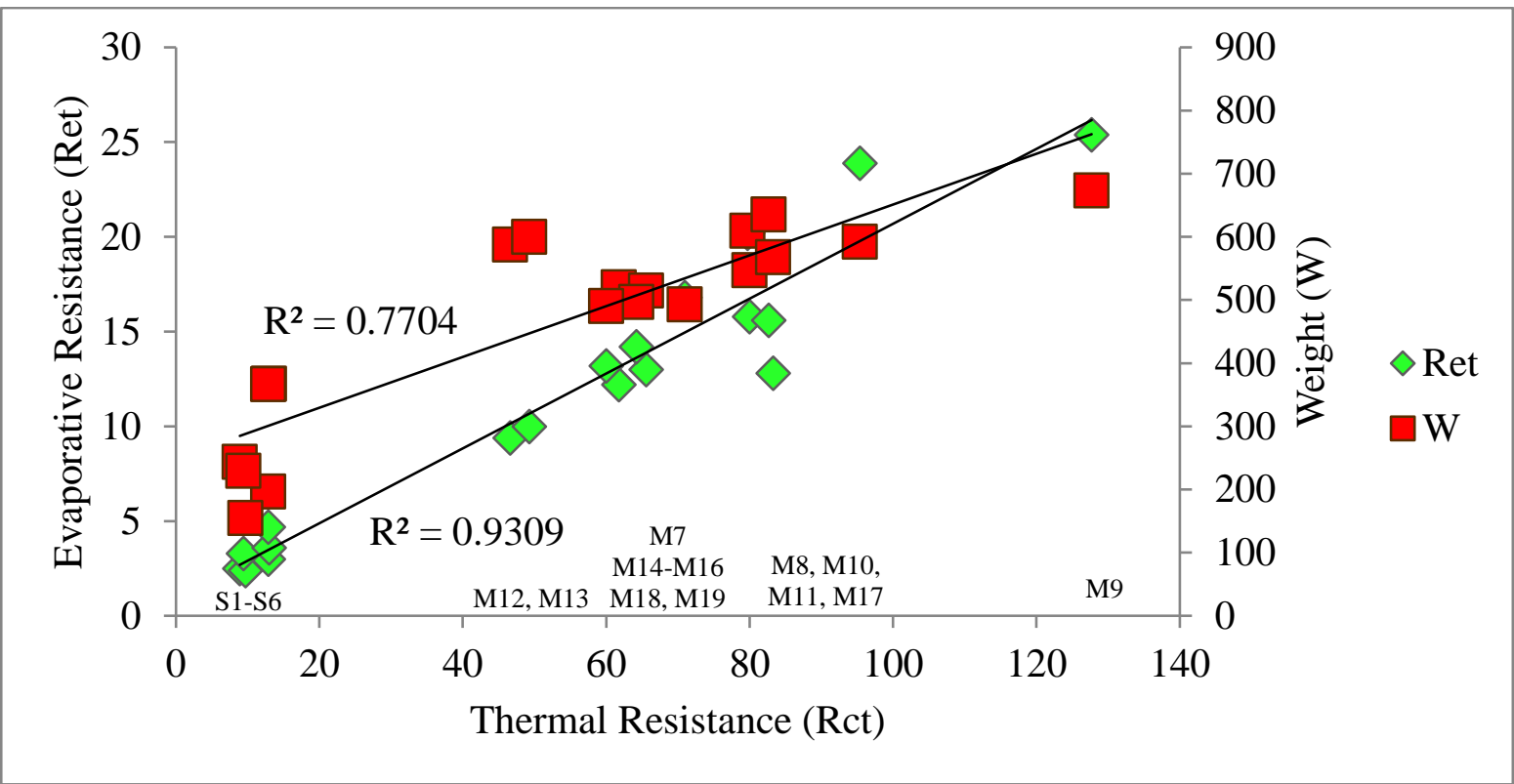

Figure 2: Association between thermal resistance with evaporative resistance and weight of the selected fabric systems

In summary, in the following section, the allocation of the fabric systems in each category is statistically (mean and standard deviation values of the significant properties of the fabric systems) verified mainly based on the significant properties ( $\mathrm{R}_{\mathrm{ct}}, \mathrm{W}, \mathrm{R}_{\mathrm{et}}$, and/or WSS) and primary construction parameters (number/types/arrangements of fabric layers in the system, and/or woven/nonwoven/permeable structure of the fabric layers in the system) that affect the thermal protective and thermo-physiological comfort performances. Additionally, the key characteristics related to the development process of the fabric systems within the categories are discussed in order to get an understanding about how to upgrade or develop new fabric systems with improved thermo-physiological comfort performance while maintaining the required thermal protective performance.

\section{Group 1}

As per the previous discussion, the multi-layered fabric systems belonging to Group 1 possess a TPPI value: $\geq 0.45$ and these fabric systems have high thermal protective performance. Depending upon the typical TCPI values of the clusters, the thermo-physiological comfort performance of Group 1 fabric systems can be divided as: low thermo-physiological comfort performance (TCPI value $<0.52$ ), medium thermo-physiological comfort performance 
$(0.52 \leq$ TCPI value $\leq 0.76)$, and high thermo-physiological comfort performance (TCPI value > 0.76). By combining the thermal protective and thermo-physiological comfort performances, Group 1 fabric systems can be categorized as: $\mathrm{TP}_{\mathrm{H}} \mathrm{TC}_{\mathrm{L}}$ (TPPI value $\geq 0.45$ and TCPI value $<$ $0.52), \mathrm{TP}_{\mathrm{H}} \mathrm{TC}_{\mathrm{M}}(\mathrm{TPPI}$ value $\geq 0.45,0.52 \leq \mathrm{TCPI}$ value $\leq 0.76)$, and $\mathrm{TP}_{\mathrm{H}} \mathrm{TC}_{\mathrm{H}}$ (TPPI value $\geq 0.45$ and TCPI value $>0.76)($ Figure 1$)$

The fabric systems (M8-M13, M17-M18) in the $\mathrm{TP}_{\mathrm{H}} \mathrm{TC}_{\mathrm{L}}$ category possess high thermal resistance or $R_{c t}$ (Mean \pm Standard Deviation of the $R_{c t}$ values of the fabric systems belonging to this category: $80 \pm 27^{\circ} \mathrm{K} \cdot \mathrm{m}^{2} / \mathrm{W} \cdot 10^{-3}$ ) that greatly increases the thermal protective performance. In general, a fabric system with high $\mathrm{R}_{\mathrm{ct}}$ lowers the transmission of conductive, convective, and/or radiative heat transfer under the flame exposure, depending upon the configuration of the fibers/yarns/fabrics (based on the amount of trapped dead air) in the fabric system [7, 8]. This lower heat transmission through the fabric systems aids in reducing the skin temperature of the firefighters, resulting in less burn. This situation increases the thermal protective performance of the fabric system. On the other hand, a high evaporative resistance or $\mathrm{R}_{\mathrm{et}}$ (Mean \pm Standard Deviation of the $R_{\text {et }}$ values of the fabric systems belonging to this category: $16 \pm 6$ $\mathrm{m}^{2} . \mathrm{Pa} / \mathrm{W}$ ) and/or low water/sweat spreading speed or WSS (Mean \pm Standard Deviation of the WSS values of the fabric systems belonging to this category: $1.5 \pm 1.3 \mathrm{~mm} / \mathrm{s}$ ) of the fabric systems in the $\mathrm{TP}_{\mathrm{H}} \mathrm{TC}_{\mathrm{L}}$ category greatly decreases the thermo-physiological comfort performance $[5,29]$. If the $\mathrm{R}_{\mathrm{et}}$ of a fabric system is high, it will not facilitate the transmission of sweat vapor from firefighters' bodies to the ambient environment. Additionally, the transmission of liquid sweat from firefighters' bodies becomes low if the WSS of a fabric layer that is in contact with firefighters' bodies is low. This kind of ineffective transmission of sweat vapor and liquid sweat lowers the wet metabolic-heat transfer from the wearers' body to the ambient environment and generates heat stress. As a result, the thermo-physiological comfort performance of the fabric system is lower. 
In order to further understand the differences in thermal protective and thermo-physiological comfort performance of the fabric systems belonging to the $\mathrm{TP}_{\mathrm{H}} \mathrm{TC}_{\mathrm{L}}$ category, the construction parameters of these fabric systems were also thoroughly investigated. Notably, the M9 fabric system of this category possesses the highest thermal protective performance and the lowest thermo-physiological comfort performance; whereas, the M18 fabric system possesses the lowest thermal protective performance and the highest thermo-physiological comfort performance (see Figure 1). The M9 fabric system also possesses less number of fabric layers (3 fabric layers) in comparison to the number of fabric layers (5 fabric layers) in the M18 fabric system; however, the thickness and weight of the M9 fabric system is much higher than the M18 fabric system. Notably, although the outer and middle layers of these two fabric systems are similar, the constructions of their inner layer(s) are completely different. The inner layer of the M9 fabric system is an aramid regenerated nonwoven felt [i.e., front view of the inner layer, Figure 3(a)] quilted with a 50\% meta-aramid/50\% FR viscose rayon woven fabric [i.e., back view of the inner layer, Figure 3(b)]. On the other hand, the M18 fabric system possesses three aramid fiber based inner layers: a nonwoven fabric [Figure 4(a)], a nano nonwoven fabric [(Figure 4(b)], and a woven fabric [(Figure 4(c)]. The inner layer or thermal liner in the M9 fabric system is a felted nonwoven, generally produced by matting, condensing, and pressing fibers together [30]; therefore, its thickness/weight is higher than the combined three inner layers in the M18 fabric system. Thus, the inner layer of the M9 fabric system can trap a lot of dead air in comparison to the inner layers of the M18 fabric system. As a result, the thermal protective performance of the M9 fabric system is much higher than the M18 fabric system. As mentioned before, both M9 and M18 fabric systems comprise similar types of semi-permeable moisture barriers. However, the presence of a lightweight, thin inner layer in the M18 fabric system can facilitate the passing of the air through the system, especially through the moisture barrier present in the middle layer of the system. Notably, quilting of the nonwoven felt with a $50 \%$ metaaramid/50\% FR viscose rayon woven fabric created needle holes on the inner layer of the M9 
fabric system due to stitching; but, these holes did not contribute in any way to pass the air through the M9 fabric system. As a result, the air permeability (AP) of the M18 fabric system $\left(0.8 \mathrm{~cm}^{3} / \mathrm{cm}^{2} / \mathrm{s}\right)$ is slightly higher than the M9 fabric system $\left(0 \mathrm{~cm}^{3} / \mathrm{cm}^{2} / \mathrm{s}\right)$. Due to its comparatively high AP, the evaporative resistance $\left(R_{\mathrm{et}}\right)$ of the M18 fabric system $\left(14.2 \mathrm{~m}^{2} . \mathrm{Pa} / \mathrm{W}\right)$ is considerably lower than the M9 fabric system $\left(25.4 \mathrm{~m}^{2} . \mathrm{Pa} / \mathrm{W}\right)$; which means, sweat vapor can evaporate more easily through the M18 fabric system than it can in the M9 fabric system. As a result, the thermo-physiological comfort performance of the M18 fabric system is much higher than the M9 fabric system. In summary, the construction parameters (nonwoven, felt, semipermeable) of the inner and middle layers primarily control the thermal protective and thermophysiological comfort performance of the fabric systems belonging to the $\mathrm{TP}_{\mathrm{H}} \mathrm{TC}_{\mathrm{L}}$ category, respectively [31].

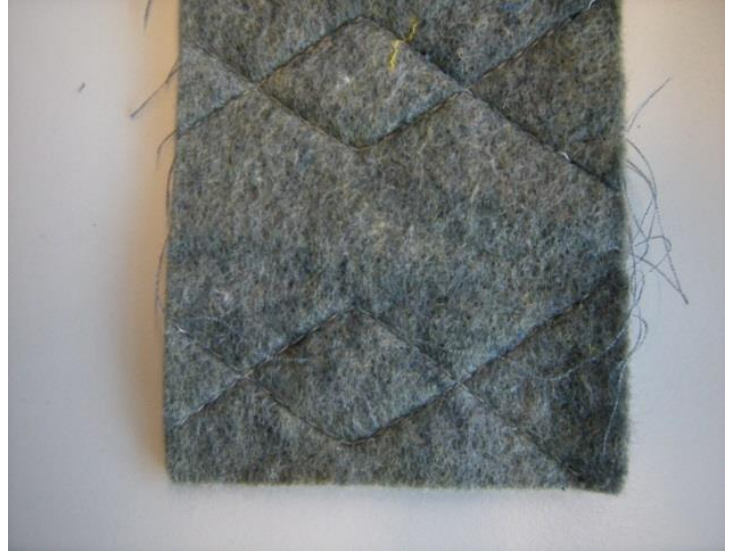

a)

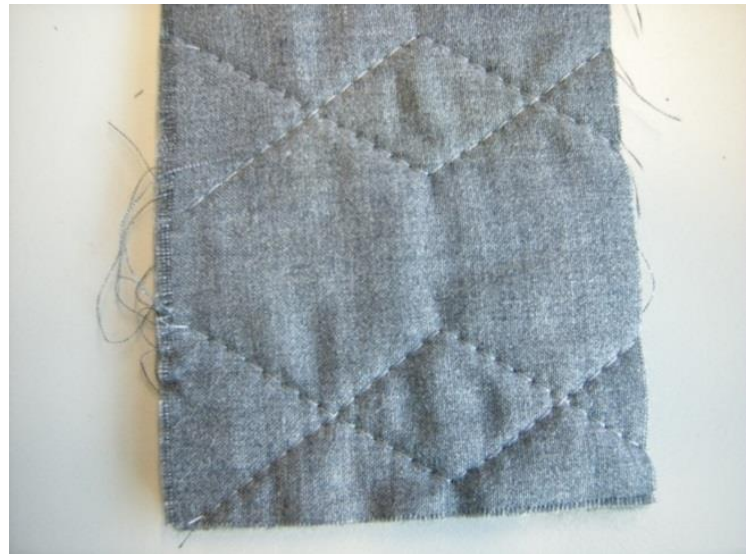

b)

Figure 3: Inner layer of the M9 fabric system [a) aramid regenerated nonwoven felt (front view of the inner layer with felt) quilted with b) $50 \%$ meta-aramid/50\% FR viscose rayon woven fabric (back view of the inner layer, which shows the quilting of felt with woven fabric)]

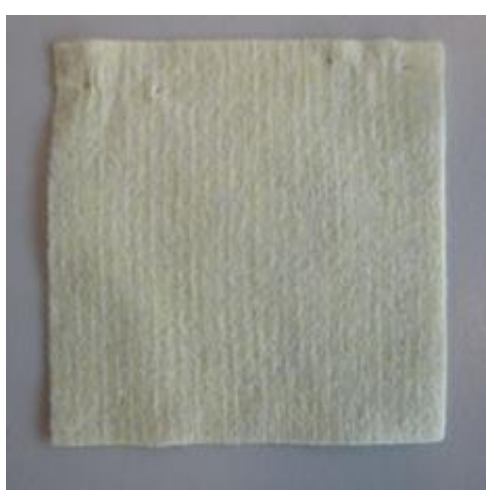

a)

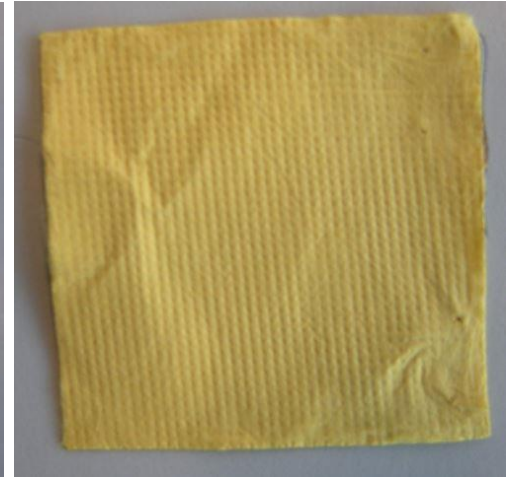

b)

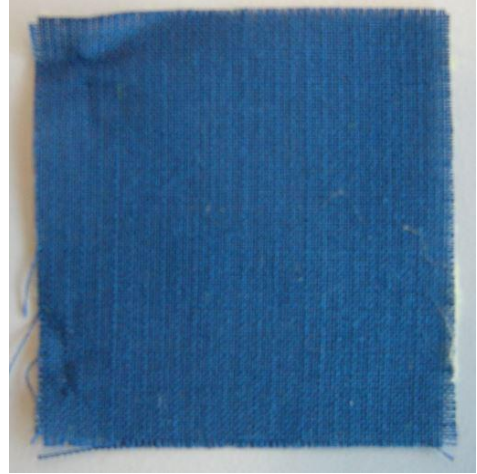

c) 
Figure 4: Inner layers of the M18 fabric system [a) a nonwoven fabric, b) a nano nonwoven fabric, c) a woven fabric]

The fabric systems in the $\mathrm{TP}_{\mathrm{H}} \mathrm{TC}_{\mathrm{M}}$ category (fabric systems: M7, M14-16) possess lower thermal resistance or $R_{c t}$ (Mean \pm Standard Deviation of the $R_{c t}$ values of the fabric systems belonging to this category: $67 \pm 7^{\circ} \mathrm{K} \cdot \mathrm{m}^{2} / \mathrm{W} \cdot 10^{-3}$ ) than the fabric systems which belong to the $\mathrm{TP}_{\mathrm{H}} \mathrm{TC}_{\mathrm{L}}$ category (Mean \pm Standard Deviation of the $\mathrm{R}_{\mathrm{ct}}$ values of the fabric systems belonging to this category: $80 \pm 27^{\circ} \mathrm{K} \cdot \mathrm{m}^{2} / \mathrm{W} \cdot 10^{-3}$ ). Eventually, based on the above discussion, fabric systems in the $\mathrm{TP}_{\mathrm{H}} \mathrm{TC}_{\mathrm{M}}$ category possess lower thermal protective performance than the fabric systems which belong to the $\mathrm{TP}_{\mathrm{H}} \mathrm{TC}_{\mathrm{L}}$ category. Nevertheless, as discussed before, comparatively lower evaporative resistance or $R_{\mathrm{et}}$ (Mean \pm Standard Deviation of the $R_{\mathrm{et}}$ values of the fabric systems belonging to this category: $14 \pm 3 \mathrm{~m}^{2} . \mathrm{Pa} / \mathrm{W}$ ) and higher water/sweat spreading speed or WSS (Mean \pm Standard Deviation of the WSS values of the fabric systems belonging to this category: $2.7 \pm 1.2 \mathrm{~mm} / \mathrm{s}$ ) of the fabric systems in the $\mathrm{TP}_{\mathrm{H}} \mathrm{TC}_{\mathrm{M}}$ category results in increased thermo-physiological comfort performance in comparison to the fabric systems belonging to the $\mathrm{TP}_{\mathrm{H}} \mathrm{TC}_{\mathrm{L}}$ category (Mean \pm Standard Deviation of the $\mathrm{R}_{\mathrm{et}}$ and WSS values of the fabric systems belonging to this category: $16 \pm 6 \mathrm{~m}^{2} . \mathrm{Pa} / \mathrm{W}$ and $1.5 \pm 1.3 \mathrm{~mm} / \mathrm{s}$, respectively).

It is also evident from Figure 1 that the thermal protective and thermo-physiological comfort performance of the fabric systems belonging to the $\mathrm{TP}_{\mathrm{H}} \mathrm{TC}_{\mathrm{M}}$ category varies widely. In particular, the M7 fabric system possesses the highest thermal protective performance and the lowest thermo-physiological comfort performance in this category; whereas, the M15 fabric system possesses the lowest thermal protective performance and the highest thermo-physiological comfort performance. In comparison, the M7 fabric system is comprised of a lower number of fabric layers (3 fabric layers) than the M15 fabric system (4 fabric layers); however, the thermal resistance of the M7 fabric system is higher than the M15 fabric system. The middle layer (moisture barrier) of the M7 fabric system contains PTFE dots (on the back side of the moisture barrier) arranged towards the inner layer of the system (Figure 5). It is believed that 
these raised dots (each dot has a diameter and height of $\sim 4 \mathrm{~mm}$ and $\sim 2 \mathrm{~mm}$, respectively) trap dead air by creating a gap between the middle layer and inner layer of the M7 fabric system, which enhances the thermal resistance of the fabric system. The middle layer (moisture barrier) of the M15 fabric system does not contain any dots which results in the low thermal resistance of the M15 fabric system (Figure 6). The higher thermal resistance of the M7 fabric system results in a higher thermal protective performance than the M15 fabric system. Notably, due to this difference in the dotted and un-dotted structure of the middle layer, the M15 fabric system facilitates the passing of air through its structure, especially through the semi-permeable moisture barrier. As a result, the air permeability (AP) of the M15 fabric system $\left(1 \mathrm{~cm}^{3} / \mathrm{cm}^{2} / \mathrm{s}\right)$ is much higher than the M7 fabric system (impermeable with $0 \mathrm{~cm}^{3} / \mathrm{cm}^{2} / \mathrm{s}$ ). Due to this comparatively high AP, the evaporative resistance $\left(\mathrm{R}_{\mathrm{et}}\right)$ of the M15 fabric system $\left(12.2 \mathrm{~m}^{2} . \mathrm{Pa} / \mathrm{W}\right)$ is considerably lower than the M7 fabric system (20.2 $\left.\mathrm{m}^{2} . \mathrm{Pa} / \mathrm{W}\right)$. Eventually, sweat vapor will evaporate more easily through the M15 fabric system than the M7 fabric system. As a result, the thermo-physiological comfort performance of the M15 fabric system is much higher than the M7 fabric system. In summary, the dotted and un-dotted structure in the middle layer of a fabric system plays a significant role on the thermal protective and thermo-physiological comfort performance of the fabrics by creating the air gap between fabric layers.

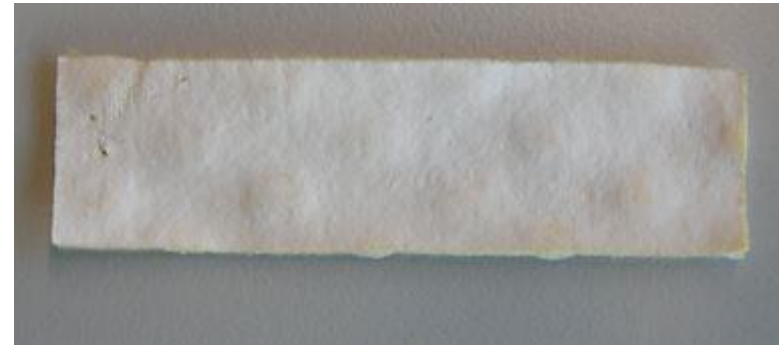

a)

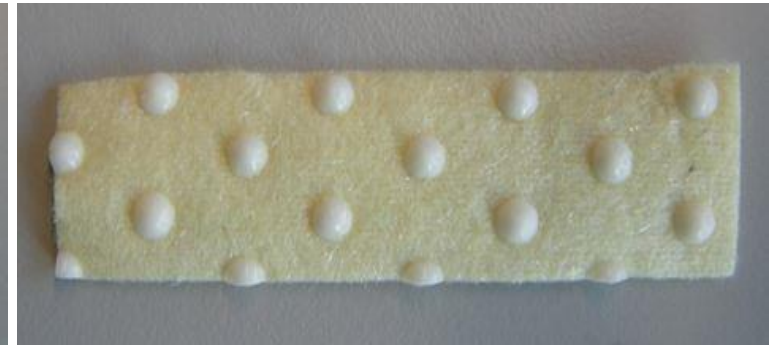

b)

Figure 5: Middle layer of the M7 fabric system [a) front view with PTFE coating, b) back view with PTFE dots having a diameter and height of $4 \mathrm{~mm}$ and $2 \mathrm{~mm}$, respectively] 


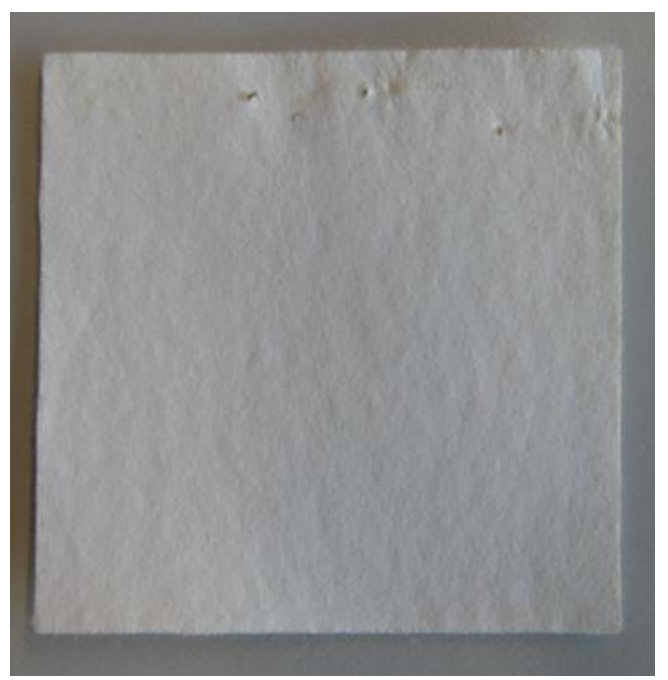

a)

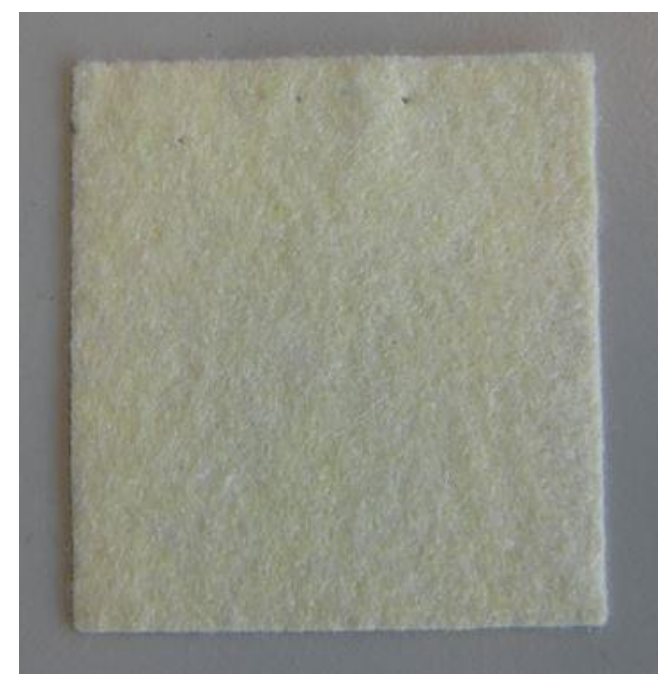

b)

Figure 6: Middle layer of the M15 fabric system [a) front view with PTFE coating, b) back view with no dots]

Furthermore, the $\mathrm{TP}_{\mathrm{H}} \mathrm{TC}_{\mathrm{L}}$ fabric systems are generally manufactured by conventional technologies like spinning, loom weaving, coating, and/or nonwoven processes which covert fibers into fabrics; whereas, fabric systems belonging to the $\mathrm{TP}_{\mathrm{H}} \mathrm{TC}_{\mathrm{M}}$ category are manufactured by the latest technology such as nanotechnology, electrospinning, etc. So, it can be inferred that the $\mathrm{TP}_{\mathrm{H}} \mathrm{TC}_{\mathrm{L}}$ category fabric systems could be reconstructed from their original fibers in order to improve their thermo-physiological comfort performance as $\mathrm{TP}_{\mathrm{H}} \mathrm{TC}_{\mathrm{M}}$ fabric category by incorporating the latest technologies such as nanofibers, aerogel insulator, smart textiles, etc., [31]. This improved fabric system could possess both thermal protective performance and improved thermo-physiological comfort performance. It is also notable that category $\mathrm{TP}_{\mathrm{H}} \mathrm{TC}_{\mathrm{H}}$ could give high thermal protection along with a high degree of thermo-physiological comfort to firefighters; however, no fabrics tested actually fell into this category. Fabrics which fall into the $\mathrm{TP}_{\mathrm{H}} \mathrm{TC}_{\mathrm{H}}$ category would be most desirable to firefighters.

\section{Group 2}

As discussed earlier, the single- and multi-layered fabric systems belonging to Group 2 possess: $0.05 \leq$ TPPI $<0.45$. These fabric systems comprise low thermal protective performance. Based upon the typical TCPI values of the clusters, the thermo-physiological comfort performance of these Group 2 fabric systems can be divided into these categories: low thermo- 
physiological comfort performance (TCPI value < 0.52), medium thermo-physiological comfort performance $(0.52 \leq$ TCPI value $\leq 0.76)$, and high thermo-physiological comfort performance (TCPI value > 0.76). By combining the thermal protective and thermo-physiological comfort performances, Group 2 fabric systems can be categorized as: $\mathrm{TP}_{\mathrm{LTC}} \mathrm{TC}_{\mathrm{L}}(0.05 \leq \mathrm{TPPI}<$ 0.45, TCPI value $<0.52), \mathrm{TP}_{\mathrm{LTC}} \mathrm{TC}_{\mathrm{M}}(0.05 \leq \mathrm{TPPI}$ value $<0.45,0.52 \leq \mathrm{TCPI}$ value $\leq 0.76)$, and $\mathrm{TP}_{\mathrm{L}} \mathrm{TC}_{\mathrm{H}}(0.05 \leq \mathrm{TPPI}$ value $<0.45, \mathrm{TCPI}$ value $>0.76)($ Figure 1$)$.

Interestingly, all of the Group 2 fabric systems in this study belong to categories $\mathrm{TP}_{\mathrm{L}} \mathrm{TC}_{\mathrm{H}}$ $(\mathrm{S} 1, \mathrm{~S} 4)$ and $\mathrm{TP}_{\mathrm{L}} \mathrm{TC}_{\mathrm{M}}(\mathrm{S} 2, \mathrm{~S} 5, \mathrm{~S} 6, \mathrm{M} 19)$. The fabric systems in these categories possess low thermal resistance or $R_{c t}$ (Mean \pm Standard Deviation of the $R_{c t}$ values of the fabric systems belonging to these two categories: $11 \pm 2{ }^{\circ} \mathrm{K} \cdot \mathrm{m}^{2} / \mathrm{W} \cdot 10^{-3}$ ) that greatly decreases the protective performance; but, the low weight or $\mathrm{W}$ (Mean \pm Standard Deviation of the $\mathrm{W}$ values of the fabric systems belonging to these two categories: $260 \pm 88 \mathrm{~g} / \mathrm{m}^{2}$ ) and low evaporative resistance or $\mathrm{R}_{\mathrm{et}}$ (Mean \pm Standard Deviation of the $\mathrm{R}_{\mathrm{et}}$ values of the fabric systems belonging to these two categories: $3 \pm 0.8 \mathrm{~m}^{2} . \mathrm{Pa} / \mathrm{W}$ ) of these fabric systems greatly increases the thermo-physiological comfort performance. Theoretically, the single-layered fabric systems (S1, S2, S4, S5, S6) within these two categories are a highly porous woven fabric; and, the $\mathrm{R}_{\mathrm{ct}}$ and $\mathrm{R}_{\mathrm{et}}$ of these fabric systems are low. Hence, these fabric systems cannot provide proper insulation to firefighters under fire exposures; but, these fabric systems can effectively transmit the metabolic heat and sweat vapor from firefighters' bodies to their ambient environment. As a result, the thermal protective and thermo-physiological comfort performances of these fabric systems are low and high, respectively $[11,29,32]$. Additionally, the lower $\mathrm{W}$ of these fabric systems due to the fact they are a single-layered structure also results in less physiological burden on firefighters, which helps to enhance the thermo-physiological comfort performance of the systems. As M19 is the only multi-layered fabric system belonging to these two categories, the thermal protective performance of this fabric system is the highest due to its high $R_{c t}$ (see Figure 1). However, the thermo-physiological comfort performance of the M19 fabric system is not the 
lowest among all the fabric systems within these two categories as one might expect. Within these categories, the S5 fabric system possesses the worst thermo-physiological comfort performance (see Figure 1). Actually, the S5 fabric system which is made using 100\% FR treated $\left(\right.$ Proban $^{\circledR}$ ) fiber has the lowest water/sweat spreading speed (WSS) among all the fabric systems belonging to $\mathrm{TP}_{\mathrm{LTC}}(\mathrm{S} 1, \mathrm{~S} 4)$ and $\mathrm{TP}_{\mathrm{L}} \mathrm{TC}_{\mathrm{M}}(\mathrm{S} 2, \mathrm{~S} 5, \mathrm{~S} 6, \mathrm{M} 19)$ categories. The S5 fabric system ineffectively transmits the liquid sweat away from the body due to the FR treatment on the surface of the system, and thus exhibits the worst thermo-physiological comfort performance. Interestingly, the $\mathrm{S} 4$ fabric system has the highest $(6.8 \mathrm{~mm} / \mathrm{s})$ WSS among all the fabric systems (within the categories of $\mathrm{TP}_{\mathrm{L}} \mathrm{TC}_{\mathrm{H}}$ and $\mathrm{TP}_{\mathrm{L}} \mathrm{TC}_{\mathrm{M}}$ ) and this system was manufactured using inherently fire resistant meta-aramid fiber. So, the thermo-physiological comfort performance of this fabric system is the highest within the categories. The $\mathrm{S} 2$ fabric system like the $\mathrm{S} 4$ fabric system is also manufactured from $100 \%$ inherently fire resistant meta-aramid fibers; but, its WSS and thermo-physiological comfort performance is lower than the $\mathrm{S} 4$ fabric system (see Table 1 and Figure 1). This finding can be explained based on the differences in their weave design. Through microscopic investigation of the weave design, it has been found that both S2 and S4 fabric systems were manufactured by using $2 / 1$ twill weave; however, the number of weft per $\mathrm{cm}$ in S2 fabric system (warp per $\mathrm{cm}$ : weft per $\mathrm{cm}=30: 25$ ) is higher than the S4 fabric system (warp per $\mathrm{cm}$ : weft per $\mathrm{cm}=30: 20$ ). This higher number of weft yarns inhibits the spreading of the liquid sweat through the S2 fabric system, which lowers the WSS and thermo-physiological comfort performance of the system.

\section{Summary and Conclusion}

The developed categorization tool provides an important insight into the best balance between thermal protective as well as thermo-physiological comfort performances of fabric systems. This tool distributes the systems in 6 categories (i.e., high-thermal-protection/low-comfort, high-thermal-protection/medium-comfort, high-thermal-protection/high-comfort, lowthermal-protection/low-comfort, low-thermal-protection/medium-comfort, and low-thermal- 
protection/high-comfort performance) by balancing the protective and comfort performances. Additionally, this study provides an insight into how fabric systems' properties (e.g., thermal resistance, evaporative resistance, weight, sweat spreading speed) and constructions (number/types of fabric layers, and/or woven/nonwoven/permeable structure of fabric layers in the system) affect this balance.

In general, single- and multi-layered fabric systems with low and high thermal resistance can be categorized as low and high thermal protective performance based systems, respectively. However, multi-layered fabric systems generally possess high evaporative resistance and can be categorized as with low thermo-physiological comfort performance in comparison to the single-layered fabric systems; this categorization could be affected by the weight of the systems as well as sweat spreading speed of the skin contacted fabric layer in the systems. Notably, the multi-layered fabric systems manufactured with conventional macro-fiber based nonwoven fabric layers or thermal liners possess low comfort performance in comparison to the systems manufactured with contemporary nanofibers based nonwoven thermal liners. The comfort performance of these systems also depends upon the permeable structure of its moisture barrier. Additionally, types (dotted or un-dotted arrangements, FR treatment, fiber composition and weave design) of the individual fabric layers in the systems could substantially influence their categorizations. Although a fabric system with high protective and comfort performances is desired, no commercially available systems belong to this category yet. For the firefighters' safety, it is expected to apply state-of-the-art technology in future to manufacture fabric systems with high protective and comfort performances.

The effective use of this tool could reduce the heat stress of on-duty firefighters during physical activities without compromising their protection in relation to burn injuries. The 6 categories presented within this tool could aid clothing manufacturers in selecting appropriate fabric systems. For example, fabric systems selected for wildland firefighters' protective cloth- 
ing could possess low protective performance in comparison to systems used for structural firefighters' clothing. But, fabric systems selected for both of these ensembles could have an equal level of comfort performance. The categorized fabric systems could also guide to fire stations' clothing procurement managers in selecting appropriate systems based on clothing required to provide protection and comfort during fire ground operations.

This study focuses on measuring and categorizing the thermal protective and thermophysiological comfort performances of the fabric systems only. Obviously, the design of the clothing (e.g., microclimate air gaps between the clothing and wearers' bodies, closures, size fit) made from such fabric systems have an impact on the protection and comfort of firefighters. In future, the protective and comfort performances of whole firefighters' clothing could be measured and the technique for developing the categorization tool of this study could be applied for categorizing the protective and comfort performances. Additionally, the technique could be applied widely as protection and comfort are equally important in other protective clothing (e.g., chemical/biological protective clothing). These kinds of improved and newly developed tools would be realistic with specific knowledge on protective textiles; and could lead to the development of protective fabric systems and clothing ensembles with improved comfort performance, particularly important for different workers (firefighters, industrial labors). Newly developed clothing could provide better occupational safety for the workers.

\section{References}

1. Brushlinsky, N. N., Ahrens, M., Sokolov, S. V., \& Wagner, P. (2016). World fire statistics. Russia: Center of Fire Statistics- International Association of Fire and Rescue Services, 162.

2. Fahy, R. F., LeBlanc, P. R., \& Molis, J. L. (2016, June). Firefighter fatalities in the United States - 2015. USA: National Fire Protection Association, 1-35.

3. Haynes, H. J. G., \& Molis, J. L. (2016, November). U.S. firefighter injuries- 2015. USA: National Fire Protection Association, 1-38. 
4. Mandal, S., Annaheim, S., Pitts, T., Camenzind, M., \& Rossi, R. (2017a). Studies of the thermal protective performance of fabrics used in firefighters' clothing under fire exposures: from small-scale to hexagon tests. Textile Research Journal. DOI: https://doi.org/10.1177/0040517517723020

5. Mandal, S., Camenzind, M., Annaheim, S., \& Rossi, R. (2017b). Evaluation of heat and flame protective performance of clothing using manikins. In R. Nayak \& R. Padhye (Eds.), Manikins for Textile Evaluation (pp. 199-223). United Kingdom: Woodhead Publishing.

6. Rossi, R. (2003). Firefighting and its influence on the body. Ergonomics, 46(10), 1017-1033.

7. Shalev, I., \& Barker, R. L. (1983). Analysis of heat transfer characteristics of fabrics in an open flame exposure. Textile Research Journal, 53(8), 475-482.

8. Song, G., Paskaluk, S., Sati, R., Crown, E. M., Dale, J. D., \& Ackerman, M. (2011). Thermal protective performance of protective clothing used for low radiant heat protection. Textile Research Journal, 81(3), 311-323.

9. Annaheim, S., Pitts, T., Morrissey, M., Camenzind, M., Rossi, R. M. (2016, October). Prediction of thermo-physiological impact of fire fighter protective clothing. $11^{\text {th }}$ International Meeting for Manikins and Modeling, Suzhou, China.

10. Fontana, P., Saiani, F., Grütter, M., Croset, J., Capt, A., Camenzind, M., Morrissey, M., Rossi, R. M., Annaheim, S. (2017). Exercise intensity dependent relevance of protective textile properties for human thermo-physiology. Textile Research Journal, 87(12), 14251434.

11. Houshyar, S., Padhye, R., \& Nayak, R. (2017). Effect of moisture-wicking materials on the physical and thermo-physiological comfort properties of firefighters' protective clothing. Fibers and Polymers, 18(2), 383-389.

12. Mandal, S., Annaheim, S., Camenzind, M., \& Rossi, R. (2017c). Evaluation of thermophysiological comfort of clothing using manikins. In R. Nayak \& R. Padhye (Eds.), Manikins for Textile Evaluation (pp. 115-140). United Kingdom: Woodhead Publishing. 
13. Mandal, S., Song, G., Ackerman, M., Paskaluk, S., \& Gholamreza, F. (2013). Characterization of textile fabrics under various thermal exposures. Textile Research Journal, 83(10), 1005-1019.

14. Mandal, S. (2016). Studies of the thermal protective performance of textile fabrics used in firefighters' clothing under various thermal exposures. University of Alberta, Edmonton, Canada.

15. Song, G., Cao, W., \& Gholamreza, F. (2011b). Analyzing thermal stored energy and effect on protective performance. Textile Research Journal, 81(11), 120-135

16. Barker, R. L., \& Lee, Y. M. (1987). Analyzing the transient thermophysical properties of heat-resistant fabrics in TPP exposures. Textile Research Journal, 57(6), 331-338.

17. Torvi, D. A., \& Dale, J. D. (1998). Effect of variation in thermal properties on the performance of flame resistant fabrics for flash fires. Textile Research Journal, 68(11), 787-796.

18. ISO 3801:1977. (1977). Textiles - woven fabrics - determination of mass per unit length and mass per unit area. Geneva, Switzerland: ISO.

19. ISO 5084:1996. (1996). Textiles - determination of thickness of textiles and textile products. Geneva, Switzerland: ISO.

20. ISO 11092:2014. (2014). Textiles - Physiological effects - Measurement of thermal and water-vapour resistance under steady-state conditions (sweating guarded-hotplate test). Geneva, Switzerland: ISO

21. ISO 9237:1995. (1995). Textiles - determination of the permeability of fabrics to air. Geneva, Switzerland: ISO.

22. AATCC 1995:2017. (2017). Liquid moisture management properties of textile fabrics. North Carolina, USA: AATCC.

23. ISO 9151:2016. Protective clothing against heat and flame - determination of heat transmission on exposure to flame. 
24. Mandal, S., Camenzind, M., Annaheim, S., \& Rossi, R. (Submitted May 3, 2018). Modeling for predicting the thermal protective and thermo-physiological comfort performances of fabrics used in firefighters' clothing. Textile Research Journal

25. Mitsa, T. (2010). Temporal Data Mining. USA: CRC Press.

26. 18640-1:2018. Protective clothing for firefighters - physiological impact - part 1: measurement of coupled heat and moisture transfer with the sweating TORSO.

27. Mandal, S., Camenzind, M., Annaheim, S., \& Rossi, R. (2018). Characterization and modelling of thermal protective performance of fabrics under different levels of radiant-heat exposures. Journal of Industrial Textiles. DOI: 10.1177/1528083718760801

28. Mandal, S., \& Song, G. (2014). An empirical analysis of thermal protective performance of fabrics used in protective clothing. The Annals of Occupational Hygiene, 58(8), 10651077.

29. Song, G., \& Mandal, S. (2016). Testing and evaluating thermal comfort of clothing ensembles. In L. Wang (Ed.), Performance Testing of Textiles: Methods, Technology, and Applications (pp. 39-64). United Kingdom: Woodhead Publishing.

30. Albrecht, W., Fuchs, H., \& Kittelmann, W. (2006). Nonwoven Fabrics. USA: Wiley.

31. Song, G., Mandal, S., \& Rossi, R. (2016). Thermal Protective Clothing for Firefighters. England: Woodhead Publishing.

32. Sun, G., Yoo, H. S., Zhang, X. S., \& Pan, N. (2000). Radiant protective and transport properties of fabrics used by wildland firefighters. Textile Research Journal, 70(7), 567-573. 